Elsevier

JIM 04722

\title{
A rapid and sensitive screening method for the detection of anti-2-acetylaminofluorene immunoglobulins *
}

\author{
Lawrence K. Silbart ${ }^{1}$, Gerald Nordblom ${ }^{2}$, David F. Keren ${ }^{1}$, Dean S. Wise, Jr. ${ }^{3}$, \\ Pamela M. Lincoln ${ }^{1}$ and Leroy B. Townsend ${ }^{3}$ \\ ${ }^{1}$ Department of Pathology, Biochemistry Section, The University of Michigan, Ann Arbor, MI 48109, U.S.A., \\ ${ }^{2}$ Warner Lambert Corporation, 2800 Plymouth Road, Ann Arbor, MI 48105, U.S.A., \\ and ${ }^{3}$ Department of Medicinal Chemistry, The University of Michigan, Ann Arbor, MI 48109, U.S.A.
}

(Received 5 November 1987, accepted 25 November 1987)

A method is described in which anti-2-acetylaminofluorene immunoglobulins may be detected using a simple and sensitive screening procedure. The method is based on immunoglobulin binding of an ${ }^{125} \mathrm{I}$ derivatized 2-aminofluorene radiotracer. Tracer binding is not isotype specific, and thus the method is useful for the detection of either IgG or IgA. Competitive binding experiments with the radiotracer were used to determine the specificity of immunoglobulin response by measurement of cross-reactivity with related ligands. This method allows quantitation of the immune response to the carcinogen in serum and other biological fluids (i.e., intestinal secretions).

Key words: Anti-carcinogen immunoglobulin; Anti-carcinogen screening; 2-Acetylaminofluorene

Correspondence to: L.K. Silbart, Department of Pathology, Biochemistry Section, The University of Michigan, Room M2210 Med. Sci. I, Ann Arbor, MI 48109, U.S.A.

* This work was supported in part by a grant from the Smokeless Tobacco Research Council.

Abbreviations: AAF, acetylaminofluorene; BSA, bovine serum albumin; CHES, cyclohexylaminoethane sulfonic acid; CFA, complete Freund's adjuvant; Cl-T, chloramine-T; DMF, dimethylformamide; DMSO, dimethylsulfoxide; DMBA, 7,12dimethylbenz(a)anthracene; EDAC, 1-ethyl-3-(3-dimethylaminopropyl)carbodiimide; ELISA, enzyme-linked immunosorbent assay; HPLC, high performance liquid chromatography; IgA, immunoglobulin A; IgG, immunoglobulin G; IR, infrared; MES, 2-( $N$-morpholino)ethanesulfonic acid; NMR, nuclear magnetic resonance spectroscopy; $\mathrm{PAH}$, polyaromatic hydrocarbon; PBS, phosphate-buffered saline; pHP-AAF, $N$ 2-(4-hydroxyphenylacetamido)fluorene; PT, Tween-supplemented phosphate-buffered saline; SAF, $N$-2-fluorenylsuccinamic acid; TLC, thin layer chromatography; UV, ultraviolet.

\section{Introduction}

2-Acetylaminofluorene (2-AAF) is a wellstudied model compound for the investigation of arylamine/arylacetamide carcinogenesis in several animal species. Upon absorption, the parent compound becomes a substrate for a variety of metabolic enzymes, some of which detoxify the compound, while others produce reactive chemical intermediates substantially more toxic to the organism than the parent compound (Miller et al., 1960; Miller and Miller, 1964). $N$-hydroxylation of 2-AAF to the arylhydroxamic acid (Miller et al., 1960; Frederick et al., 1982) and subsequent phase 2 conjugation via sulfation (DeBaun et al., 1968; Meerman et al., 1981; Lai et al., 1985, 1987), glucuronidation (Sakai et al., 1978), N,O- 
acyltransfer (Weeks et al., 1978), or $O$-acetylation (Flamang and Kadlubar, 1986) can result in the formation of electrophilic intermediates capable of damaging cellular macromolecules. The formation of DNA adducts which result from the reaction of electrophilic 2-AAF metabolites with nucleophilic centers in the DNA helix, have been postulated to serve as a committed initiation step in the neoplastic transformation of cells (Garner et al., 1984; Miller and Miller, 1981).

Several investigators have attempted to prevent the sequence of metabolic events leading to DNA damage by immobilizing the parent carcinogen immunologically prior to activation and toxicity (Creech and Franks, 1937; Franks and Creech, 1939; Peck and Peck, 1971; Moolton and Capparell, 1978; Moolton et al., 1978; Tompa et al., 1979; Moolton et al., 1981). Using parenteral immunization, these studies have demonstrated the ability to produce a systemic humoral immunity (IgG) to several carcinogens. Although some studies have shown that the presence of this humoral immunity correlated with an inhibition of chemically induced neoplasia, others have shown an increase in tumorigenesis following immunization (Creech and Franks, 1937; Curtis et al., 1978). Moolton et al. (1978) suggested that the development of a mucosal immunity $(\operatorname{IgA})$ to 7,12-dimethylbenz(a)athracene (DMBA) and related PAH carcinogens could facilitate excretion of the carcinogen by preventing absorption into the body. Mice immunized with an intraperitoneal, followed by an intragastric dose of a fluorinated derivative of DMBA-BSA conjugate showed increased levels of $\left[{ }^{3} \mathrm{H}\right]$ benzo(a)pyrene binding in the $\gamma$-globulin fraction of fecal extracts following ingestion of the radiolabelled carcinogen. However, no direct determination of the presence of IgA-anti-PAH was made in these studies.

Recent studies in our laboratory aimed at stimulating a mucosal immune response against 2-AAF (Keren et al., 1987) have created a need for a simple, sensitive method for screening large numbers of biological fluids for anti-AAF immunoglobulins. In the present report we describe the synthesis of a radiotracer bearing the aminofluorene hapten covalently coupled to $p$-hydroxyphenylacetic acid, which is subsequently iodinated with $\mathrm{Na}^{125} \mathrm{I}$. Binding of this radiotracer serves as the basis of a sensitive immunoassay for the detection of anti-AAF immunoglobulins. Cross-reactivity studies using this radiotracer have provided information on the specificity of the immunoglobulin response to AAF-protein conjugates. Competitive microELISA experiments have confirmed the presence of IgG anti-AAF immunoglobulins in sera from immunized rats and rabbits testing positive by the ${ }^{125} \mathrm{I}$ binding assay described. Similarly, IgA-anti-AAF immunoglobulins have been detected in rabbit intestinal secretions following immunization with AAF-carrier protein conjugates using this method (Keren et al., 1987).

\section{Materials and methods}

Succinic anhydride, 2-acetylaminofluorene (2AAF), 1-ethyl-3-(3-dimethylaminopropyl)carbodiimide- $\mathrm{HCl}$ (EDAC), bovine serum albumin, ovalbumin, thyroglobulin, $p$-nitrophenyl phosphate, and fluorene were obtained from Sigma Chemical Co. (St. Louis, MO). Anthracene, 2aminofluorene (2-AF), 2-nitrofluorene, 9-aminofluorene- $\mathrm{HCl}$, carbazole, biphenyl, 1-aminofluorene, 2-aminoanthracene, 3-aminofluoranthene, and 3-amino-9-ethylcarbazole were obtained from Aldrich Chemical Co. (Milwaukee, WI). New Zealand White rabbits were purchased from Langshaw, Sprague-Dawley rats were purchased from Charles River, ELISA microtiter plates were obtained from Dynatech, Tween 20 was purchased from Baker Chemical Co., and goat anti-rat IgG (GARTG) was purchased from Cappel. All other buffers, solvents and reagents were analytical grade or better.

Melting points were determined with a Thomas Hoover capillary melting point apparatus and are uncorrected. The IR spectra were recorded on a Perkin Elmer 281 spectrophotometer and values are expressed in $\mathrm{cm}^{-1}$. The ${ }^{1} \mathrm{H} \mathrm{nmr}$ spectra were obtained on a Bruker WP270SY (270 MHz) spectrophotometer. The chemical shift values are reported in parts per million on the $\delta$ scale with tetramethylsilane as the internal reference. The microanalyses were performed by $\mathrm{M}-\mathrm{H}-\mathrm{W}$ Laboratories, Phoenix, AZ. The thin layer chromatography (TLC) was performed on silica gel-GF (Analtech) plates. The detection of compounds on 


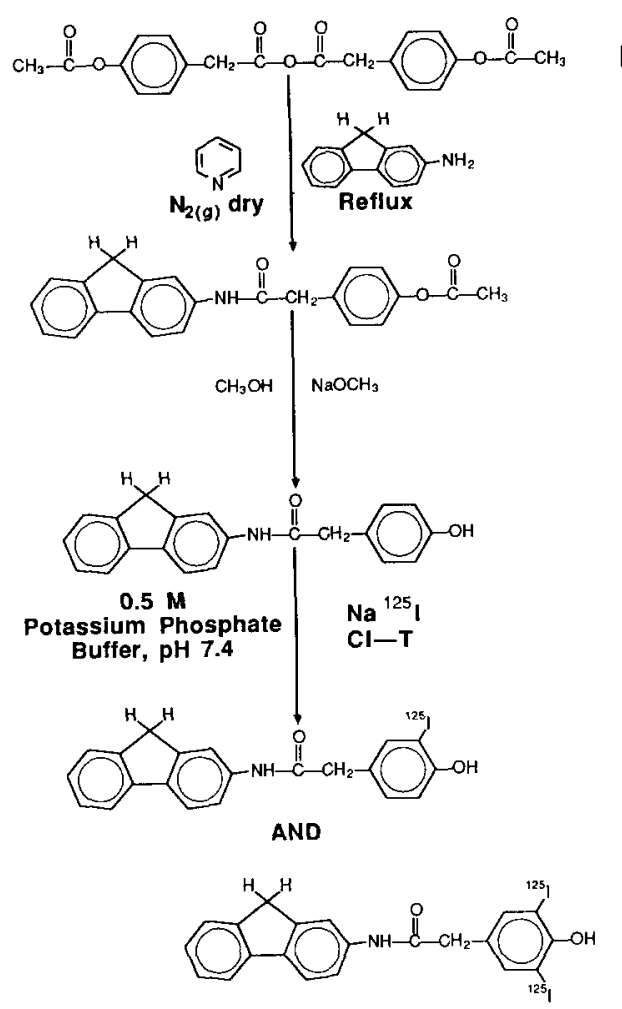

[1]

[2]

[3]

[4]

[5]

Fig. 1. Synthesis of the ${ }^{125}$ I-labelled radiotracer. Each numbered compound was isolated, purified and analyzed as described in the materials and methods section. Compounds [4] and [5] were isolated by reverse phase HPLC following radioiodination.

TLC was made using UV light. The evaporation of solvents was carried out under reduced pressure with a rotary evaporator using a water aspirator at the temperature noted.

\section{Synthesis of the ${ }^{125} I$ radiolabel}

N-2-(4-acetoxyphenylacetamido)fluorene [2]. The synthetic method used to prepared the ${ }^{125} I$ radiolabel is summarized in Fig. 1. The synthesis of the p-hydroxyphenylacetic anhydride [1] was accomplished using the method of Nordblom et al. (1981)*.

2-Aminofluorene $(1.2 \mathrm{~g}, 6.62 \mathrm{mmol})$ was dissolved in dry pyridine $(100 \mathrm{ml})$. p-Acetoxyphenylacetic anhydride $(3.85 \mathrm{~g}, 10.4 \mathrm{mmol})$ was then added and the mixture was heated at reflux for 1

\footnotetext{
* The yield of anhydride can be greatly increased by omission of the $\mathrm{NaHCO}_{3}$ wash step described.
}

h. When complete, the mixture was acidified with $1 \mathrm{~N} \mathrm{HCl}$ and extracted with methylene chloride $(4 \times 200 \mathrm{ml})$. The combined organic layer was washed successively with $100 \mathrm{ml}$ portions of $\mathrm{H}_{2} \mathrm{O}$, $1 \mathrm{M} \mathrm{NaHCO}, \mathrm{H}_{2} \mathrm{O}, 1 \mathrm{~N} \mathrm{HCl}$ and $\mathrm{H}_{2} \mathrm{O}$. The methylene chloride was dried over $\mathrm{MgSO}_{4}$, filtered, and the solvent removed in vacuo. The resulting residue was dissolved in a minimum quantity of hot toluene, filtered through a Celite/decolorizing charcoal filter cake and allowed to crystallize. Collection of the solid yielded $0.84 \mathrm{~g}$ of $\mathrm{N}-2$-(4acetoxyphenylacetamido)fluorene ([2], 35\% yield, $\mathrm{MP}=189-192^{\circ} \mathrm{C}$ with decomposition). IR $(\mathrm{KBr}$ pellet) $V_{\max }: 3305,1755,1660,1590,1510 \mathrm{~cm}^{-1}$. ${ }^{1} \mathrm{H}$ NMR (DMSO-d ${ }_{6}$ ): $2.24\left(\mathrm{~s}, 3 \mathrm{H}, \mathrm{CH}_{3}\right) ; 3.66(\mathrm{~s}$, $\left.2 \mathrm{H}, \mathrm{CH}_{2}\right) ; 3.87\left(\mathrm{~s}, 2 \mathrm{H}, \mathrm{CH}_{2}\right) ; 7.06-7.92(\mathrm{~m}, 11 \mathrm{H}$, aromatic $\mathrm{H}) ; 10.25(\mathrm{~s}, 1 \mathrm{H}, \mathrm{NH}$, exchangeable with $\mathrm{D}_{2} \mathrm{O}$ ). Calculated analysis for $\mathrm{C}_{23} \mathrm{H}_{19} \mathrm{NO}_{3}$ : $\mathrm{C}$, 77.28; N, 3.92; H, 5.37. Found: C, 77.11; N, 3.93; H, 5.40 .

N-2-(4-hydroxyphenylacetamido)fluorene [3]. $N$-2-(4-Acetoxyphenylacetamido)fluorene [2] (200 $\mathrm{mg}, 0.56 \mathrm{mmol}$ ) was dissolved in dry methanol (50 $\mathrm{ml})$, and sodium methoxide $(10 \mu \mathrm{g})$ was added. The solution was heated to $40^{\circ} \mathrm{C}$ and stirred for 4 $h$. After allowing the mixture to cool to room temperature, the methanol was removed in vacuo and the remaining solid was suspended in $\mathrm{H}_{2} \mathrm{O}$ $(500 \mathrm{ml})$. The $\mathrm{pH}$ was adjusted to 2 with $1 \mathrm{~N} \mathrm{HCl}$. The aqueous suspension was extracted with methylene chloride $(4 \times 200 \mathrm{ml})$. The combined organic extract was washed twice with $\mathrm{H}_{2} \mathrm{O}$ and dried over $\mathrm{MgSO}_{4}$. The mixture was filtered and the solvent was evaporated in vacuo. The resulting solid was recrystallized from hot toluene to yield $100 \mathrm{mg}$ of $\mathrm{N}$-2-(4-hydroxyphenylacetamido)fluorene [3], (pHP-AAF, 57\% yield, $\mathrm{MP}=207-210^{\circ} \mathrm{C}$ with decomposition). IR ( $\mathrm{KBr}$ pellet) $V_{\max }, 3305,1675$, $1520 \mathrm{~cm}^{-1}$. ${ }^{1} \mathrm{H}$ NMR (DMSO-d $\left.{ }_{6}\right): 3.51(\mathrm{~s}, 2 \mathrm{H}$, $\left.\mathrm{CH}_{2}\right) ; 3.87\left(\mathrm{~s}, 2 \mathrm{H}, \mathrm{CH}_{2}\right) ; 6.68-7.94 \quad(\mathrm{~m}, 11 \mathrm{H}$, aromatic $\mathrm{H}) ; 9.24(\mathrm{~s}, 1 \mathrm{H}, \mathrm{OH}$, exchangeable with $\left.\mathrm{D}_{2} \mathrm{O}\right) ; 10.13\left(\mathrm{~s}, 1 \mathrm{H}, \mathrm{NH}\right.$, exchangeable with $\left.\mathrm{D}_{2} \mathrm{O}\right)$. Calculated analysis for $\mathrm{C}_{21} \mathrm{H}_{17} \mathrm{NO}_{2}: \mathrm{C}, 79.97 ; \mathrm{N}$, 4.44 ; H, 5.44. Found: C, 79.89; N, 4.49; H, 5.69).

\section{Radioiodination of $p H P-A A F$ [4], [5]}

$\mathrm{N}$-2-(4-hydroxyphenylacetamido)fluorene [3] (10 $\mathrm{mg}, 0.03 \mathrm{mmol}$ ) was dissolved in methanol (10 $\mathrm{ml})$. To $2.0 \mu \mathrm{l}(6.3 \mathrm{nmol})$ of this solution in a 0.5 


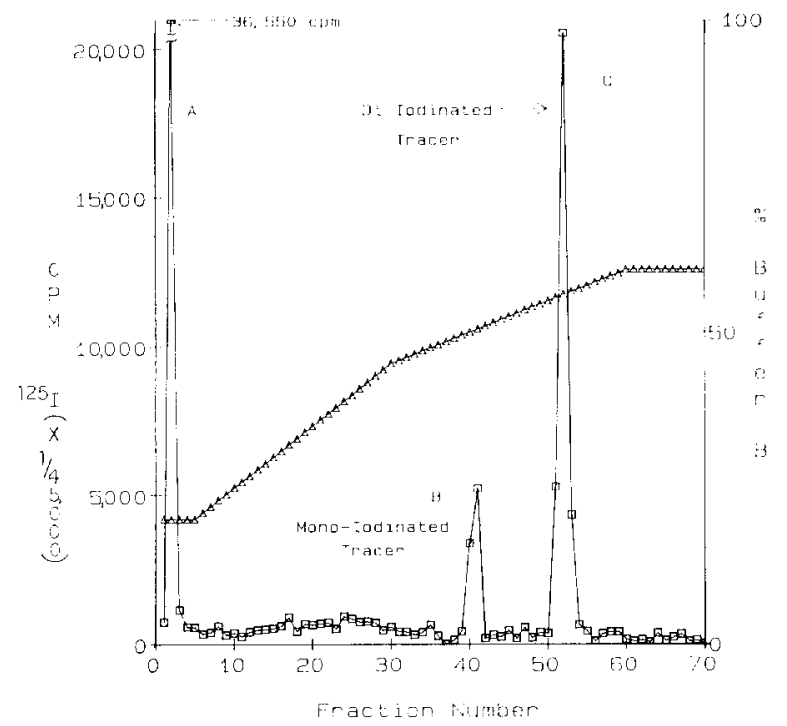

Fig. 2. HPLC elution of the ${ }^{125} \mathrm{I}$-pHP-AAF radiotracer. $(\square-\square)$ indicate the measured radioactivity contained in each fraction recovered from the HPLC column. ( $\triangle-\triangle$ ) indicates the gradient elution in \% buffer B. Buffer A: $0.05 \mathrm{M}$ potassium formate, $\mathrm{pH}$ 4.0. Buffer B: HPLC grade acetonitrile. The flow rate of elution was $1.0 \mathrm{ml} / \mathrm{min}$. Fractions of $1 \mathrm{ml}$ were collected and counted on an Eberline Miniscaler (MS-2), with an external geometry permitting $0.0022 \%$ of the total activity to be counted.

dram vial, fitted with a multi-dose septum, was added $0.5 \mathrm{M}$ potassium phosphate buffer, $\mathrm{pH} 7.4$ (buffer $\mathrm{A}, 40 \mu \mathrm{l}$ ), followed by aqueous $\mathrm{Na}^{125} \mathrm{I}(4.0$ $\mathrm{mCi}$, dissolved in $9 \mu 1$ buffer $\mathrm{A})$. The iodination was initiated with the addition of chloramine-T ( $30 \mu \mathrm{g}$ dissolved in $10 \mu 1$ of buffer $\mathrm{A}$ ). The reaction was shaken for $2 \mathrm{~min}$ and quenched with sodium metabisulfite $(30 \mu \mathrm{g}$, dissolved in $10 \mu \mathrm{l}$ buffer A). The reaction mixture (containing compound [4] and [5], Fig. 1) was injected onto an Altech RPA 600 reverse phase C-18 HPLC column and eluted initially with an isocratic $0.05 \mathrm{M}$ potassium formate buffer $(\mathrm{pH} \mathrm{4.0)/acetonitrile}$ $(80: 20, v / v)$ solvent system. A linear gradient was established from 5 to $80 \mathrm{~min}$, with a final solvent mix of $40: 60$ formate buffer/acetonitrile. The remainder of the elution was performed isocratically at the final solvent mixture ratios (Fig. 2). The solvent flow rate was held constant at 1 $\mathrm{ml} / \mathrm{min}$ throughout the elution, and $2 \mathrm{ml}$ fractions were collected for the first $30 \mathrm{~min}$ of the elution, followed by $1 \mathrm{ml}$ fractions for the remainder of the elution. The radioactivity in each fraction was counted using an Eberline Mini-Scaler (MS-2) fitted with a 6 in tube such that the external geometry would only allow a small portion of the radioactivity to be registered $(0.0022 \%)$, permitting identification of the active fractions without dilution.

The specific radioactivity of the monoiodinated tracer was determined using the method of Morris (1976), which compares the amount of bound vs. free radiolabel in parallel incubations with either doubling dilutions of iodinated tracer ('hot'), or doubling dilutions of the 'cold' carrier molecule (the pHP-AAF), each in the presence of a small but constant quantity of radiotracer and antibody. For the radiolabelled self-displacement curve, approximately doubling dilutions of isotope (presumed to be the monoiodinated radiotracer) were dispensed ranging from 5000 to $570000 \mathrm{cpm}$. A constant quantity of radiolabel was added to each tube $(11000 \mathrm{cpm})$, and the self-displacement competition was initiated with the addition of $100 \mu \mathrm{l}$ of a $1: 50000$ dilution of AF-60 rabbit anti-serum. The cold self-displacement curve was set-up in a similar fashion, only cold carrier compound ( $\mathrm{pHP}$ AAF) was added in a masses ranging from 10 pmol to 1000 pmol. An identical mass of radioisotope was added to these tubes as in the 'hot' displacement samples above $(11000 \mathrm{cpm})$, as well as the addition of the antiserum. Both sets of samples were allowed to equilibrate for $2 \mathrm{~h}$ at room temperature, followed by the separation of bound counts from free with the addition of 1.0 $\mathrm{ml}$ dextran coated charcoal (kept at $4^{\circ} \mathrm{C}$ ). The tubes were immediately centrifuged at $2400 \mathrm{rpm}$ for $5 \mathrm{~min}$. The clear supernatants (containing antibody bound counts) were transferred to clean tubes and counted in the Hydrogamma-16 gamma counter. The ratios of bound versus free counts were calculated for both sets of samples, and the amount of cold mass required to displace a known quantity of iodinated label was obtained. The specific activity of the radiotracer was determined graphically as described by Morris (1976).

\section{$N$-2-Fluorenylsuccinamic acid (SAF)}

2-Aminofluorene $(5.0 \mathrm{~g}, 28 \mathrm{mmol})$ was dissolved in dry pyridine $(150 \mathrm{ml})$ under a nitrogen atmosphere. Succinic anhydride $(7.5 \mathrm{~g}, 75 \mathrm{mmol})$ 
was added slowly with gentle stirring. The reaction was allowed to stand in the dark at room temperature with stirring for $14 \mathrm{~h}$. The pyridine was removed in vacuo using a roto-evaporator and a dry ice trap. The resulting solid was recrystallized from absolute ethanol to yield $4.52 \mathrm{~g}$ of tan needles $\left(57 \%\right.$ yield, $\mathrm{MP}=225-227^{\circ} \mathrm{C}$ with decomposition). IR (KBr pellet) $V_{\max }, 3305,1695$, $1650,1590,1510,1420 \mathrm{~cm}^{-1} \cdot{ }^{1} \mathrm{H}$ NMR (DMSO$\left.\mathrm{d}_{6}\right): 3.26\left(\mathrm{~s}, 2 \mathrm{H}, \mathrm{CH}_{2}\right) ; 3.82\left(\mathrm{~s}, 4 \mathrm{H}, \mathrm{CH}_{2}-\mathrm{CH}_{2}\right)$; 7.16-7.85 (m,7H,aromatic $\mathrm{H})$; $9.97(\mathrm{~s}, 1 \mathrm{H}, \mathrm{COOH}$, exchangeable with $\left.\mathrm{D}_{2} \mathrm{O}\right) ; 12.06(\mathrm{~s}, 1 \mathrm{~N}, \mathrm{NH}$, exchangeable with $\mathrm{D}_{2} \mathrm{O}$ ). Analysis calculated for $\mathrm{C}_{17} \mathrm{H}_{15} \mathrm{NO}_{3}$ : C, 72.58; $\mathrm{N}, 4.98 ; \mathrm{H}, 5.39$. Found: $\mathrm{C}$, 72.44; N, 5.07; H, 5.50.

\section{Optimization of conjugation conditions}

Fig. 3 illustrates the conditions of the conjugation reaction used to couple SAF to a variety of carrier proteins. 1-Ethyl-3-(3-dimethylaminopropyl)carbodiimide- $\mathrm{HCl}$ (EDAC, $45 \mathrm{mg}, 0.23 \mathrm{mmol}$ ) was dissolved in $1 \mathrm{ml}$ of $0.05 \mathrm{M} 2-(N-$ morpholino)ethanesulfonic acid (MES) buffer, $\mathrm{pH}$ 4.75. This solution was added dropwise with stirring to a solution of $66 \mathrm{mg}(0.23 \mathrm{mmol}) \mathrm{SAF}$ dissolved in $9 \mathrm{ml}$ of dimethylformamide (DMF) and allowed to stand for $1 \mathrm{~h}$ at room temperature with stirring. The carrier protein was dissolved in $0.05 \mathrm{M}$ cyclohexylaminoethane sulfonic acid buffer (CHES), pH $9.5(0.42 \mu \mathrm{mol}$ carrier protein dissolved in $42 \mathrm{ml}$ CHES buffer). The SAF solution was then added dropwise to the carrier protein solution with gentle stirring and allowed to stand for $14 \mathrm{~h}$. The solution was transferred to dialysis tubing and dialyzed against 4-5 one liter changes of phosphate-buffered saline (PBS) until the absorbance of the dialysate attained an absorbance less than 0.010 at $280 \mathrm{~nm}$. The retentate (with the exception of thyroglobulin conjugates) was filtered through a $0.45 \mu \mathrm{m}$ filter and stored in $1.5 \mathrm{ml}$ aliquots at $-20^{\circ} \mathrm{C}$.

The degree of SAF substitution per mole of carrier protein was estimated in the following manner. The protein concentration of the conjugated solution was determined by Coomassie blue dye binding assay (Bradford, 1976) and the absorbance of the conjugate solution was measured at $280 \mathrm{~nm}$. The absorbance of the carrier protein alone at a comparable concentration was estimated from a standard curve and subtracted from the latter value. The molar extinction coefficient of SAF at $280 \mathrm{~nm}$ was determined to be
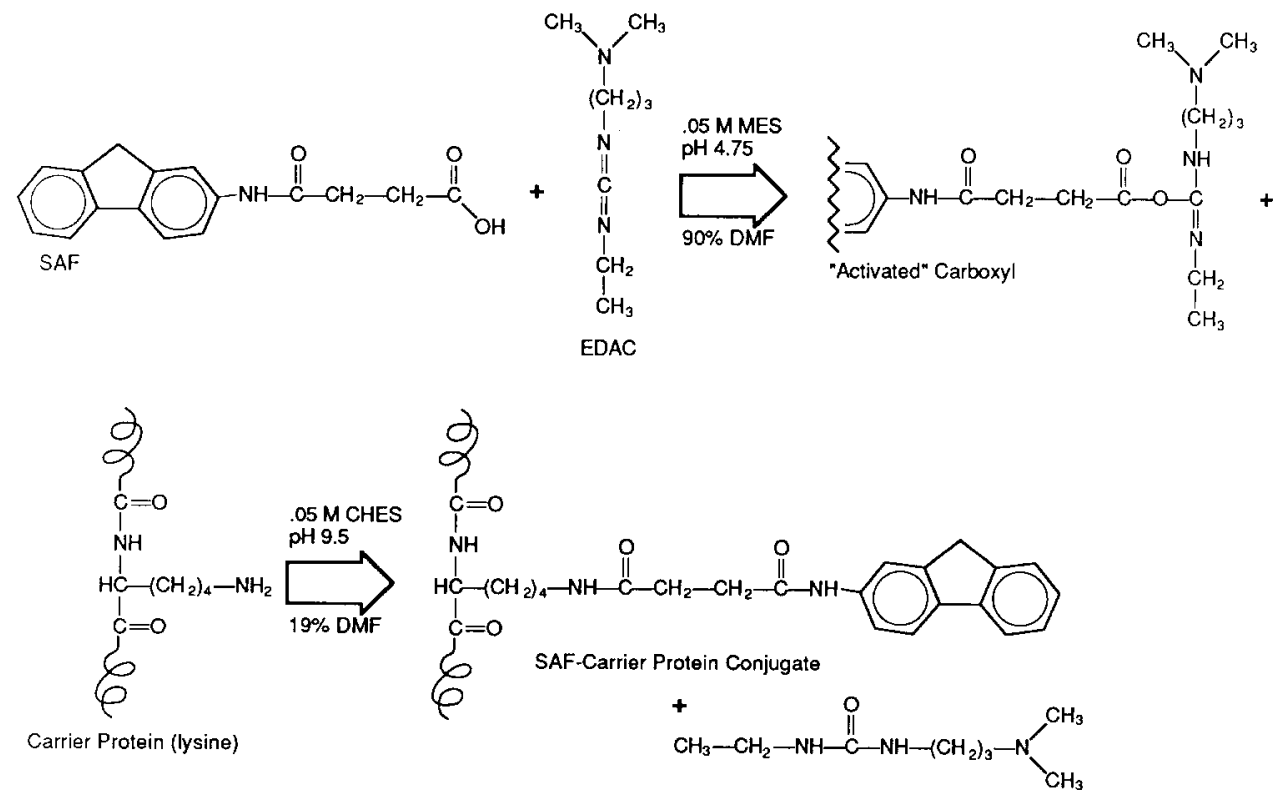

Fig. 3. Chemical coupling of SAF to carrier proteins. The conditions of the coupling reaction shown were critical to achieve a high level of substitution. Details are provided in the materials and methods section. 
$20056 \mathrm{M}^{-1} \mathrm{~cm}^{-1}$ by serial PBS dilutions at neutral $\mathrm{pH}$ from a $1 \mathrm{mg} / \mathrm{ml}$ stock solution of SAF in dimethylformamide. The residual absorbance after subtraction of the protein absorbance was presumably due to SAF and was converted to molar equivalents. The molar ratio of SAF to protein estimated by this method routinely fell in the range of $20-30$ for albumin carrier proteins.

\section{Immunization and antibody response}

Four rabbits were given multiple-site intramuscular injections containing a total of $200-400 \mu \mathrm{g}$ SAF-carrier protein conjugate in 1-2 $\mathrm{ml} 50$ : 50 complete Freund's adjuvant (CFA, PBS, $\mathrm{v} / \mathrm{v})$. SAF-carrier protein conjugate $(100 \mu \mathrm{g}$ in 1.0-1.8 ml 50:50 complete Freund's adjuvant) were given to three rats, sub-cutaneously over the hips. Similar booster immunizations were given 16 days later. Blood samples were collected weekly and tested for the capacity to bind the radiotracer in serial dilutions. Certain animals were given a second boost with the original conjugate, while others received SAF attached to a different carrier protein.

The specificity of the antibody was determined by equilibrium competition experiments involving related chemical compounds. Each competing ligand was incubated in the presence of constant quantities of iodinated tracer $(50000 \mathrm{cpm})$ and antibody (AF-60 antiserum, 1:100000 dilution). Increasing amounts of each competing ligand were added to determine the mass at which $50 \%$ inhibition of the radiolabel binding occurred $\left(I_{50}\right)$. The percent cross-reactivity was calculated relative to the $I_{50}$ of the non-iodinated tracer (pHP-AAF).

\section{Competitive microELISA}

Competitive microELISA studies were performed in parallel with the IBA as an independent confirmation of the ability to detect anti-AAF immunoglobulins. Microtiter wells were coated overnight with $100 \mu \mathrm{l}$ of $20 \mu \mathrm{g} / \mathrm{ml} \mathrm{SAF-protein}$ conjugates at $4{ }^{\circ} \mathrm{C}$ dissolved in $0.05 \mathrm{M}$ bicarbonate buffer, $1 \mathrm{mM} \mathrm{MgCl}_{2}, \mathrm{pH}$ 9.6. Test antiserum was run in wells coated with a SAFprotein conjugate containing an unrelated carrier protein to reduce non-hapten-specific protein binding. Carrier protein control wells were run in parallel experiments and subtracted as a background value from the total binding value. Antisera dilutions ranged from $1: 50$ to $1: 200$ for rat antisera and were $1: 20$ for rabbit antisera with the exception of rabbit AF-60 which was diluted $1: 20000$. For inhibition studies, increasing amounts of free 2-AAF were pre-incubated with the antisera for $1 \mathrm{~h}$ prior to its addition to the conjugate-containing well. The 2-AAF was diluted from a stock solution of $1 \mathrm{mg} / \mathrm{ml}$ in DMF. The $1000 \mathrm{ng}$ 2-AAF competition values were performed at 1\% DMF. All other experimental tubes were adjusted to contain $0.1 \%$ DMF in PBS $(v / v)$. The antigen-antibody binding was not effected at DMF concentrations of $1 \%$ or less (data not shown). These mixtures were then added to the microtiter wells and incubated at room temperature for $4 \mathrm{~h}$. The plates were then washed with several volumes of PBS containing $0.05 \%$ Tween 20 (PT), followed by the addition of alkaline phosphatase-conjugated sheep anti-rabbit IgG $(100 \mu 1$, isotype specific, affinity column purified using methods previously described) (Keren, 1979) to each well. For the rat antiserum studies, alkaline phosphatase-conjugated goat anti-rat IgG was used. After an overnight incubation, the wells were washed with PT, blotted dry, and the substrate reaction was carried out with the addition of $100 \mu \mathrm{l}$ of $p$-nitrophenyl phosphate $(1 \mathrm{mg} / \mathrm{ml}$ stock solution) dissolved in substrate buffer $(0.05 \mathrm{M}$ $\mathrm{Na}_{2} \mathrm{CO}_{3} / \mathrm{NaHCO}_{3}, 1.0 \mathrm{mM}, \mathrm{MgCl}_{2}, \mathrm{pH} 9.8$ ). The absorbance of each well was measured at 12.5, 25, 50 and $100 \mathrm{~min}$ on a Titertek microELISA reader using the $405 \mathrm{~nm}$ filter. If the $100 \mathrm{~min}$ reading exceeded the linearity of the instrument (Abs. $>2.0$ ), the $100 \mathrm{~min}$ measurement was extrapolated from the next earliest reading. Percent inhibition was calculated from the mean of two wells containing $0-1000 \mathrm{ng} 2-\mathrm{AAF}$ based on similar wells containing no 2-AAF.

\section{Results}

The reaction mixture produced from radioiodination of the pHP-AAF tracer molecule was applied to a C-18 reverse-phase HPLC column as described in the materials and methods section. 
The elution profile shown in Fig. 2 contained three major peaks. Peak A contained $83 \%$ of the total radioactivity applied to the column as free ${ }^{125} \mathrm{I}$ anion. Peak B, which eluted in fractions 39-41 (69-71 min time of elution) contained the monoiodinated radiotracer, with $5.8 \%$ of the total radioactivity. Peak $\mathrm{C}$ eluted in fractions 51-53 (81-83 min time to elution) and contained the diiodinated radiotracer molecule with $13.6 \%$ of the total activity.

The specific activity of the compound isolated in fraction 39-41 (the monoiodinated species) was calculated using the method of Morris (1976) to be $1900 \mathrm{Ci} / \mathrm{mmol}$ (following correction for counting efficiency and decay from the date of iodination). This is in close agreement with the maximum theoretical yield of $2180 \mathrm{Ci} / \mathrm{mmol}$.

Sera from rats and rabbits immunized with SAF-protein conjugates were screened for the ability to bind the ${ }^{125} \mathrm{I}$ tracer. Sera from two of three rats, and from six of ten rabbits, bound greater than $40 \%$ of the iodinated label at a $1: 1000$ serum dilution. Fig. 4 shows the complete titration curve of antisera from rabbit AF-60 at log dilutions from $1: 10$ to $1: 1000000$. Significant binding of the tracer molecule was detected at dilutions as high as 1:1000000. Similar dilutions of non-immune rabbit serum bound consistently less than $2 \%$ of the tracer. A 1:100000 dilution was chosen for the antibody specificity studies.

Data presented in Table I clearly indicates a high degree of specificity toward ligands containing a $-\mathrm{N}-\mathrm{CO}-\mathrm{CH}_{2}-$ at the 2 position of the fluorene ring. The antibody showed less affinity toward arylamines (2-aminofluorene, 2-aminoanthracene, 1-aminoanthracene, and 9-aminofluorene) than for arylacetamides, and the specificity toward the ring structures alone was slightly less than for the corresponding arylamines. Surprisingly, the antibody specificity was higher toward 2-aminoanthracene and anthracene than for 2-aminofluorene and fluorene, respectively. Less related compounds had correspondingly higher crossreactivity values, (two and four membered ring systems and ring systems with bulky side chains, e.g., 3-amino-1-ethylcarbazole).

Fig. 5 shows the level of the anti-AAF antibody binding measured by microELISA when incubated

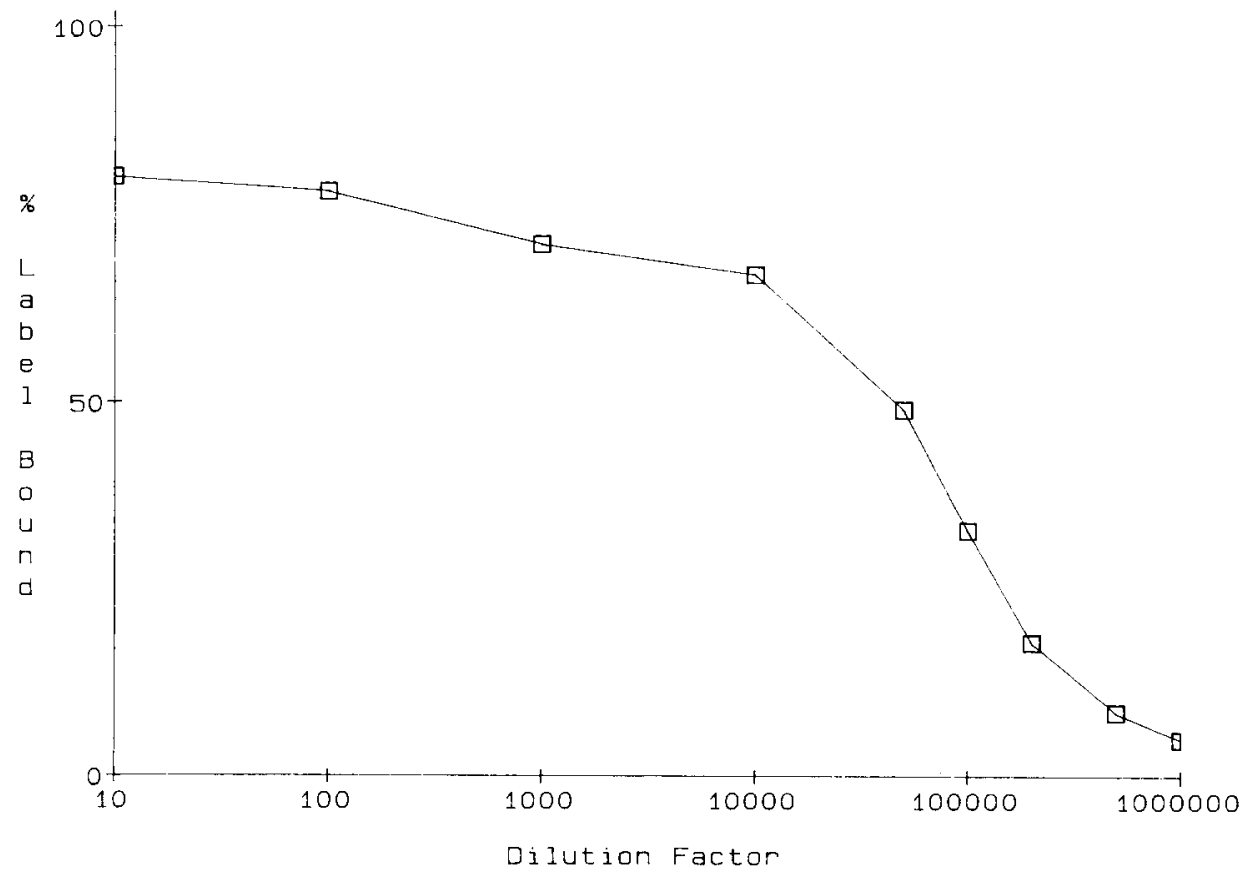

Fig. 4. Antibody titration curve. Antiserum dilutions were prepared using PBS, and the percent of the offered radiolabel (50000 cpm) was calculated. Antisera and label were allowed to equilibrate for two hours prior to separation using dextran-coated charcoal. 


\section{TABLE I}

THE MASS OF THE COMPOUNDS SHOWN BELOW DISPLACED 50\% OF THE ${ }^{125}$ I-RADIOLABEL (50000 CPM TOTAL) WHEN INCUBATED WITH A $1: 100000$ DILUTION OF ANTISERUM FROM RABBIT AF-60 $\left(I_{50}\right)$

Following a $2 \mathrm{~h}$ equilibration period at room temperature, the bound and free counts were separated using dextran-coated charcoal, and the radioactivity was quantitated using a Hydrogamma-16 gamma counter. Cross-reactivity values were calculated based on a value of 1 for the non-iodinated carrier molecule (pHP-AAF).

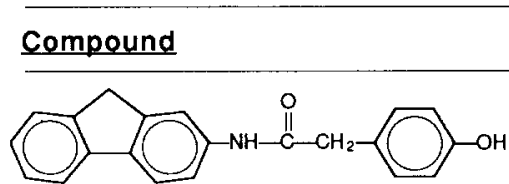

N-2-(4-Hydroxyphenylacetamido) Fluorene

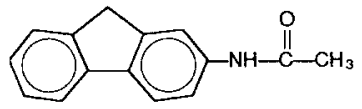

2-Acetylaminofluorene

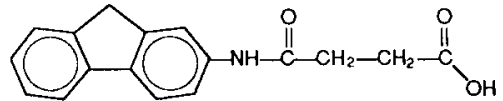

N-2-Fluorenylsuccinamic Acid

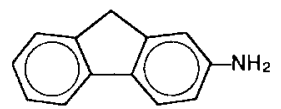

2-Aminofluorene

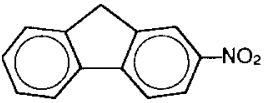

2-Nitrofluorene

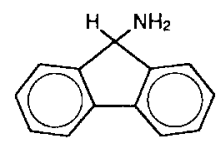

9-Aminofluorene

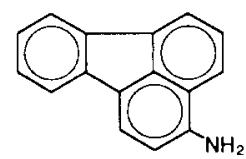

3.Aminofluoranthren

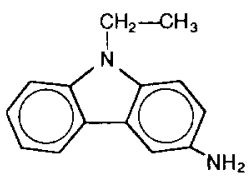

3-Amino-1-Ethylcarbazole
0.12

1

Anthracene

10.1

84

0.78

6.5

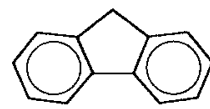

0.25

2.1

Fluorene

$\mathrm{I}_{50}$ (pmol) $\begin{aligned} & \text { Cross: } \\ & \text { Reactivi }\end{aligned}$
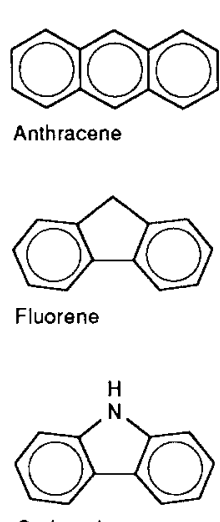

83.1

693

Carbazole

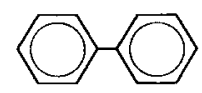

15.6

130

Biphenyl

940

7,830

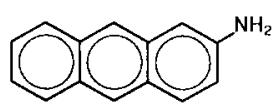

26.0

2-Aminoanthracene

2.8

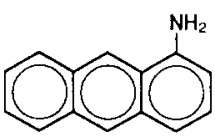

48.0

400

1-Aminoanthracene

$\mathbf{8 8 . 0}$

733

100

833

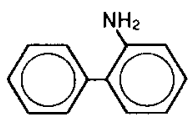

2-Aminobiphenyl

$23,300 \quad 194,000$

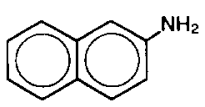

$1,800 \quad 15,000$ 


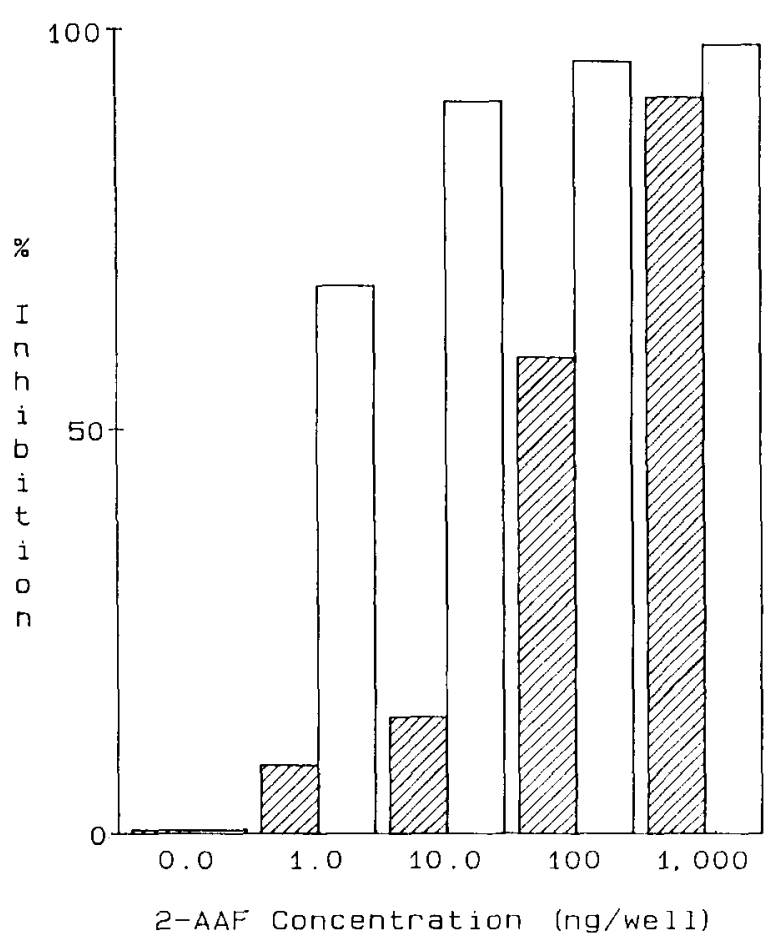

Fig. 5. Competitive microELISA. Verification of the presence of anti-2-AAF immunoglobulins was performed by competition experiments. Since the hapten (2-AAF) could not be adsorbed to the microtiter plates, carrier protein-SAF conjugates were used. The highest titer rabbit (open rectangles) and rat antisera (shaded rectangles) were incubated for $1 \mathrm{~h}$ with the designated concentration $(10 \mathrm{ng} /$ well $=100 \mathrm{ng} / \mathrm{ml}$ in the incubation system) of 2-AAF. The antiserum-AAF mixtures were then added to the microtiter plate and incubated for $4 \mathrm{~h}$ at room temperature. The plates were washed three times with copious quantities of PT, and the appropriate second antibody conjugated to alkaline phosphatase was added (either sheep anti-rabbit IgG or goat anti-rat IgG). The absorbance at $405 \mathrm{~nm}$ was measured, and the percent inhibition was calculated from similar incubations containing no 2-AAF. Values expressed are the mean of two observations.

in the presence of increasing concentrations of 2-AAF. The inhibition of binding was clearly concentration dependent and nearly $100 \%$ efficient at high 2 -AAF concentrations $(1 \mu \mathrm{g}$ /well for all rats tested). Rabbit AF-60 antiserum binding was inhibited $68 \%$ at the lowest concentration tested (1 $\mathrm{ng} /$ well) and was over $90 \%$ inhibited at a concentration of $10 \mathrm{ng} /$ well. Other rabbits in the series tested were not as sensitive to $2-\mathrm{AAF}$ inhibition, ranging from 6 to $38 \%$ inhibition at $1 \mathrm{ng} /$ well.

\section{Discussion}

The detection of antibodies directed against 2-AAF is of critical importance in recent studies on the mucosal immune response to 2-AAF-carrier protein conjugates conducted in our laboratory (Keren et al., 1987). A rapid, sensitive, hapten-specific method which could be applied to a large number of specimens was required. The immunoglobulin binding method based on an ${ }^{125}$ I-radiotracer was developed to meet this need. The 2-AAF binding assay described in this study was capable of detecting antibodies to 2-AAF at serum dilutions as high as $1: 1000000$. The presence of anti-AAF immunoglobulin in antisera from immunized rats and rabbits testing positive by the immunoglobulin binding assay was confirmed by competitive microELISA. Increasing 2-AAF concentrations caused dose-dependent inhibition of immunoglobulin binding to SAF-protein conjugates. This inhibition was nearly $100 \%$ effective at a 2 -AAF concentration of $1 \mu \mathrm{g} /$ well for both rat and rabbit antiserum.

The ${ }^{125} \mathrm{I}$ radiotracer also allowed an examination of the antibody specificity by performing cross-reactivity studies. These studies indicated that the polyclonal antibody response was directed primarily against the entire fluorenylacetamide group. Related compounds with ring substitutions or lacking the acetamide group were less able to compete with the tracer for the antibody binding sites.

This method has proven very useful in the screening of both antiserum and intestinal secretions (Keren et al., 1987) from immunized rats and rabbits. Although not isotype specific, it provides a simple, fast and sensitive screening assay for the detection of anti-AAF immunoglobulins in biological fluids.

\section{References}

Bradford, M.M. (1976) A rapid and sensitive method for the quantitation of microgram quantities of protein utilizing the principle of protein-dye binding. Anal. Biochem. 72, 248.

Creech, H.J. and Franks, W.R. (1937) Compounds synthesized from proteins and carcinogenic hydrocarbons. Am. J. Cancer 30, 555. 
Curtis, G.L., Ryan, W.L. and Stenback, F. (1978) Antibody stimulation of benzo(a)pyrene carcinogenesis. Cancer Lett. $4,223$.

DeBaun, J.R., Rowley, J.Y., Miller, E.C. and Miller, J.A. (1968) Sulfotransferase activation of $N$-hydroxy-2-acetylaminofluorene in rodent livers susceptible and resistant to this carcinogen, Proc. Soc. Exp. Biol. Med. 129, 268.

Flammang, T.J. and Kadlubar, F.F. (1986) Acetyl coenzyme A-dependent metabolic activation of $N$-hydroxy-3,2' -dimethyl-4-aminobiphenyl and several carcinogenic $N$-hydroxy arylamines in relation to tissue and species differences, other acyl donors, and arylhydroxamic acid-dependent acyltransferases. Carcinogenesis 7, 919.

Franks, W.R. and Creech, H.J. (1937) Chemoantigens and carcinogenesis: I. Am. J. Cancer 35, 203.

Frederick, C.B., Mays, J.B., Ziegler, D.M., Guengerich, F.P. and Kadlubar, F.F. (1982) Cytochrome P-450 and flavincontaining monooxygenase-catalyzed formation of the carcinogen $N$-hydroxy-2-aminofluorene and its covalent binding to nuclear DNA. Cancer Res. 42, 2671.

Garner, R.C., Martin, C.N. and Clayson, D.B. (1984) In: C.E. Searle (Ed.), Chemical Carcinogens, ACS Monograph 182, Carcinogenic Aromatic Amines and Related Compounds. American Cancer Society, Washington, DC, p. 175.

Keren, D.F. (1979) Enzyme-linked immunosorbent assay for immunoglobulin $\mathrm{G}$ and immunoglobulin $\mathrm{A}$ antibodies to Shigella flexneri antigens. Infect. Immun. 24, 441.

Keren, D.F., Lincoln, P.M., Silbart, L.K. and McDonald, R.A. (1987) Secretory IgA response in intestinal secretions to the carcinogen 2-acetylaminofluorene (2-AAF) following combined intraperitoneal and intraintestinal administration of 2-AAF carrier protein conjugates. Fed. Proc. 46, 746.

Lai, C.C., Miller, E.C., Miller, J.A. and Liem, A. (1985) $\mathrm{N}$ Sulfooxy-2-aminofluorene is the major ultimate electrophilic and carcinogenic metabolite of $N$-hydroxy-2acetylaminofluorene in the livers of infant male C57BL/6J $\times$ C3H/HeJ F1 (B6C3F1) mice. Carcinogenesis 6, 1037.

Lai, C.C., Miller, E.C., Miller, J.A. and Liem, A. (1987) Initiation of hepatocarcinogenesis in infant male B6C3F1 mice by $N$-hydroxy-2-aminofluorene or $N$-hydroxy-2acetylaminofluorene depends primarily on metabolism to $\mathrm{N}$-sulfooxy-2-aminofluorene and formation of DNA-(deoxyguanosin-8-yl)-2-aminofluorene adducts. Carcinogenesis 8,471 .

Meerman, J.H.N., Beland, F.A. and Mulder, G.J. (1981) Role of sulfation in the formation of DNA adducts from $\mathrm{N}$-hy- droxy-2-acetylaminofluorene in rat liver in vivo. Inhibition of $N$-acetylated aminofluorene adduct formation by pentachlorophenol. Carcinogenesis 2, 413.

Miller, E.C. and Miller, J.A. (1981) Mechanisms of chemical carcinogenesis. Cancer 47, 1055.

Miller, J.A. and Miller, E.C. (1964) The comparative carcinogenicities of 2-acetylaminofluorene and its $N$-hydroxy metabolite in mice, hamsters, and guinea pigs. Cancer Res. 24, 2018.

Miller, J.A., Cramer, J.W. and Miller, E.C. (1960) The $N$ - and ring-hydroxylation of 2-acetylaminofluorene during carcinogenesis in the rat. Cancer Res. 20, 950.

Moolton, F.L. and Capparell, N.J. (1978) Induction of antibodies against carcinogenic polycyclic aromatic hydrocarbons. Nature 272, 614 .

Moolton, F.L., Capparell, N.J. and Boger, E. (1978) Reduction of respiratory tract binding of benzo(a)pyrene in mice by immunization. J. Natl. Cancer Inst. 61, 1347.

Moolton, F.L., Schreiber, B., Rizzone, A., Weiss, A.J. and Boger, E. (1981) Protection of mice against 7,12-dimethylbenz(a)anthracene-induced skin tumors by immunization with a fluorinated analog of the carcinogen. Cancer Res. 41,425 .

Morris, B.J. (1976) Specific radioactivity of radioimmunoassay tracer determined by self-displacement: a re-evaluation. Clin. Chim. Acta 73, 213.

Nordblom, G.D., Webb, R., Counsel, R.E. and England, B.G. (1981) A chemical approach to solving bridging phenomena in steroid radioimmunoassays. Steroids 38, 161.

Peck, R.M. and Peck, E.B. (1971) Inhibition of chemically induced neoplasia by immunization with an antigenic carcinogen-protein conjugate. Cancer Res. 31, 1550.

Sakai, S., Reinhold, C.E., Wirth, P.I. and Thorgeirsson, S.S. (1978) Mechanism of in vitro mutagenic activation and covalent binding of $\mathrm{N}$-hydroxy-2-acetylaminofluorene in isolated liver cell nuclei from rat and mouse. Cancer Res. 38,2058 .

Tompa, A., Curtis, G., Ryan, W., Kuszynski, C. and Langenback, R. (1979) Benzo(a)pyrene antibody inhibition of benzo(a)pyrene induced mutagenesis. Cancer Lett. 7, 163.

Weeks, C.R., Allaben, W.T., Louis, S.C., Lazear, E.J. and King, C.M. (1978) Role of arylhydroxamic acid acyltransferase in the mutagenicity of $N$-hydroxy- $N$-2-fluorenylacetamide in Salmonella typhimurium. Cancer Res. 38, 613. 